\title{
LITHIUM VAPOR/AEROSOL STUDIES INTERIM SUMMARY REPORT
}

G. A. Whitlow

J. E. Bauerle

M. G. Down

W. L. Wilson

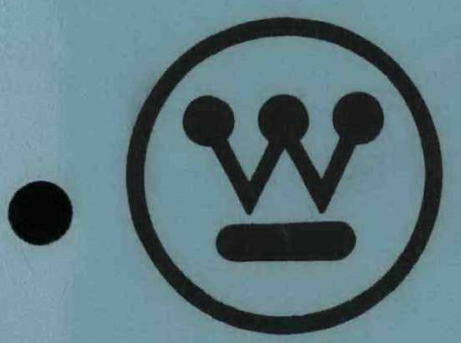

Westinghouse Advanced Reactors Division

Prepared for the U.S. Department of Energy Under Contract No. ED-78-C-08-1570.

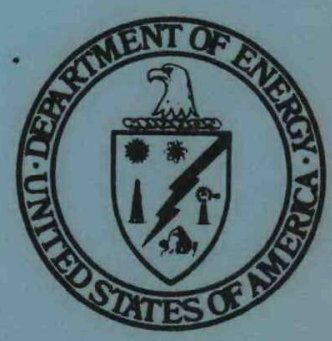




\section{DISCLAIMER}

This report was prepared as an account of work sponsored by an agency of the United States Government. Neither the United States Government nor any agency Thereof, nor any of their employees, makes any warranty, express or implied, or assumes any legal liability or responsibility for the accuracy, completeness, or usefulness of any information, apparatus, product, or process disclosed, or represents that its use would not infringe privately owned rights. Reference herein to any specific commercial product, process, or service by trade name, trademark, manufacturer, or otherwise does not necessarily constitute or imply its endorsement, recommendation, or favoring by the United States Government or any agency thereof. The views and opinions of authors expressed herein do not necessarily state or reflect those of the United States Government or any agency thereof. 


\section{DISCLAIMER}

Portions of this document may be illegible in electronic image products. Images are produced from the best available original document. 


\section{NOTICE}

This report was prepared as an account of work sponsored by the United States Government. Neither the United States nor the United States Department of Energy, nor any of their employees, nor any of their contractors, subcontractors, or their employees, makes any warranty, express or implied, or assumes any legal liability or responsibility for the accuracy. completeness or usefulness of any information, apparatus, product or process disclosed, or represents that its use would not infringe privately owned rights.

Available From:

National Technical Information Service (NTIS) U.S. Department Of Commerce

5285 Port Royal Rd., Springfield, Va. 22161
Price:

Printed Copy: $\$ 4.50$

Microfiche: $\quad \$ 3.00$ 
LITHIUM VAPOR/AEROSOL STUDIES

INTERIM SUMMARY REPORT

G. A. Whitlow

J. E. Bauerle

M. G. Down

W. L. Wilson

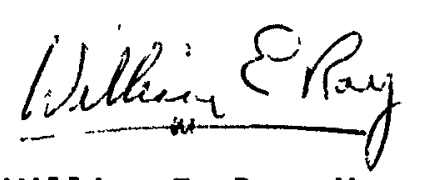

Approved: William E. Ray, Manager

Materials \& Processes Engineering

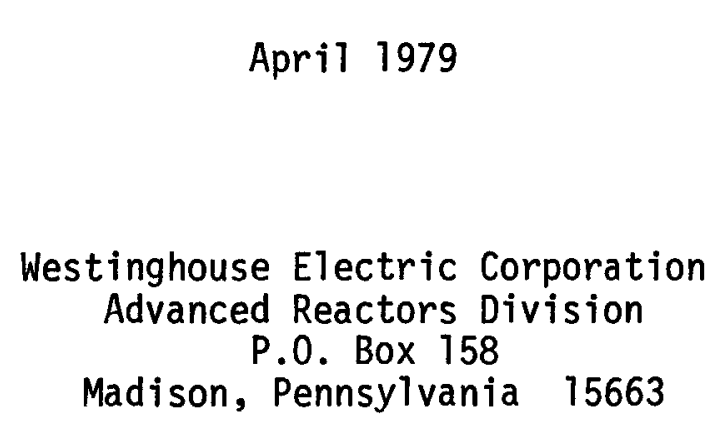

This report was prepared as an account of work sponsored by the United States Government Nerther the United States nor the United States Department of Energy, nor any of their employees, nor any of their contractors, subcontractors, or therr employees, makes any warranty, express or impled, or assumes any legal labulity or responsibulity for the accuracy, completeness or usefulness of any information, apparatus, product or process disclosed, or represents that its use would not
Westinghouse Electric Corporation P.0. Box 158
Madison, Pennsylvania 15663
Prepared for the U. S. Department of Energy Nevada Operations Office Under Contract No. ED-78-C-08-1570


This report summarizes the initial results of a Department of Energy contract with Westinghouse, Advanced Reactors Division (ARD) entitled - Lithium Vapor/Aerosol Studies and covers the work performed during the period June 15, 1978 to November 15, 1978. The following people contributed to the work contained in this report:
W. E. Ray
- Westinghouse ARD
G. A. Whitlow
- Westinghouse ARD
W. L. Wilson
- Westinghouse ARD
L. Kardos
- Westinghouse ARD
F. G. Arcella
- Westinghouse R\&D
J. E. Bauerle
- Westinghouse R\&D
M. G. Down
- Westinghouse R\&D 


\section{CONTENTS}

Section

Page

Abstract

v

Introduction 1

1 Technical Background 2

1.1 Alkali Metal Aerosols - Formation

1.2 Literature Search

1.3 Laser Beam Extinction and Visible Scattering by Alkali Metal Aerosol Particles

1.3.1 Experimental Estimation of Beam Extinction 1.3.2 Particle Size Effects

$2 \quad$ Facilities and Materials

3 Experimental Techniques

4 Results and Discussion

5 Conclusions

6 Recommendations

$7 \quad$ References

Distribution 
The temperature/cover gas pressure regime, in which detectable lithium aerosol is formed in a static system has been mapped for argon and helium cover gases using a portable He-Ne laser device. At $538^{\circ} \mathrm{C}$ (1000年), lithium aerosol particles were observed over the range 0.5 to 20 torr and 2 to 10 torr for argon and helium respectively. Results indicate that. conditions of $538^{\circ} \mathrm{C}\left(1000^{\circ} \mathrm{F}\right)$ and a pressure of $10^{-1}-10^{-2}$ torr represent a border line case in which thermal aerosol may be detectable in argon. The aerosol particle density, however, at these temperatures and pressures, would be so low that the percentage loss in laser beam intensity is likely to be $<1 \% /$ meter. With helium as the support gas this intensity loss would be even smaller. In addition, the experimental conditions in this study were more conducive to aerosol formation than in a fusion reactor. For example, the bell jar system provided high thermal gradients which would be absent in a reactor cavity. Also, long equilibration times were allowed for the formation of aerosol. In the real reactor system, very high intensity mechanical and thermal disturbances will be made to the liquid lithium. These disturbances, particularly transient increases in lithium vapor pressure appear to be capable of producing high concentrations of optically-dense aerosol. A more detailed study is, therefore, proposed using the basic information generated in these preliminary experiments, as a starting point. Areas recommended include the kinetics of aerosol formation and the occurrence of supersaturated vapor during rapid vapor pressure transients, and also the effect of lithium agitation (falls, jets, splashing, etc.) on aerosol formation. 


\section{INTRODUCTION}

Since the late 1960 's, the concept of producing electric power by inertial confinement fusion (ICF), using lasers and other high energy beams, has received increasing attention. In the reactor chamber, enough energy is supplied by the laser beam to heat and confine the deuterium-tritium fuel pellet long enough for the reaction

$$
\mathrm{D}+\mathrm{T} \rightarrow \mathrm{He}+\mathrm{n}+17.6 \mathrm{Mev}
$$

to take place. This reaction, which occurs in a pulsed mode at frequencies of the order of one to ten per second, produces neutrons, alpha particles, $x$-rays, and other debris. In several ICF reactor designs, protection of the inside wall of the reactor chamber from the damaging effects of the fusion products is achieved by a lithium blanket. In addition to providing first-wall protection, this liquid lithium blanket must(1):

1. Convert the fusion energy into thermal energy,

2. Provide for efficient removal of the thermal energy,

3. Breed enough tritium to replace the tritium burned in the fusion reaction, and

4. Maintain the required vacuum in the fusion chamber.

Lawrence Livermore Laboratory (LLL) workers have developed a first-wall protection system termed the lithium waterfall concept(2). This arrangement features a thick, continuously recycled wall of falling 1 iquid lithium that protects the first structural wall from direct exposure to the microexplosion. Each shot interrupts the water fall effect, which re-establishes itself between shots. Recent LLL studies have examined falls comprised of a large number of closely packed, round lithium jets ${ }^{(3)}$. In all of these concepts, the lithium is continuously pumped to the top of the vacuum chamber through a reservior that separates the first structural wall 
from the pressure vesse1. A small fraction of the lithium circulates as the primary coolant to the heat exchanger, and the return flow of lithium from the heat exchanger is injected at and provides protection to the top of the chamber. With the large volume and flowrates involved and the interactions of the fusion reaction, considerable quantities of lithium vapor are generated in the reactor chamber. Chamber pressures and lithium temperatures are nominally $10^{-1}$ to $10^{-2}$ torr and $538^{\circ} \mathrm{C}\left(1000^{\circ} \mathrm{F}\right)$. Under certain pressures and temperatures, conditions in the chamber may be conducive to the formation of lithium aerosol particles, and any interaction of the laser beam with these particles may have serious consequences in the uniform compression of the fuel pellet and the accomplishment of the fusion reaction.

Accordingly, Westinghouse has been funded to examine the temperature-pressure relationship for lithium aerosol formation, as an initial step towards establishing the likelihood of aerosols being formed and causing beam attentuation. The general program objective was to ascertain the formation of lithium aerosols in the temperature range 306 to $538^{\circ} \mathrm{C}\left(583\right.$ to $1000^{\circ} \mathrm{F}$ ) as a function of pressure, using a helium-neon laser beam as the means of aerosol detection. A laser beam was selected as the monitoring instrument, because it is sensitive to small quantities of aerosol particles in the atmosphere and its visibility to the naked eye is affected by very small losses in beam attenuation. Thus, it provided a relatively simple, semi-quantitative detection technique limited only by the capacity of the human eye to see the red beam in a darkened experimental enclosure.

\section{TECHNICAL BACKGROUND}

\subsection{Alkali Metal Aerosols - Formation}

Although measurements of the vapor pressure associated with liquid metals such as lithium and sodium are well established, the formation of aerosol particles above such liquids has only recently been recognized. It has been observed that under certain conditions of temperature and cover gas, the metal atoms, which constitute the vapor, can agglomerate into small particles which may themselves settle out or be transported into the cover gas system. The 
exact processes involved are poorly understood, although it is recognized that heat transport, mass transport, nucleation, agglomeration, and gravitational settling all play a part.

An aerosol can be defined as a system composed of solid or liquid particles dispersed in a gas. The size of these particles is generally in the range $10^{-2}$ to $10 \mu \mathrm{m}$. The case of an aerosol above a liquid metal pool can be further described as a condensation (or thermal) aerosol, formed when supersaturated vapors condense. The formation of a thermal alkali metal aerosol requires, then, not only a source of metal vapor but also a supporting gas. This gas may mix with the vapor either by convection (static system) or forced flow (sweep gas system). This supporting gas serves several functions other than cooling. Firstly, it increases the likelihood of coagulation (self-condensation) and prevents the vapor from condensing rapidly on walls and nearby surfaces. Secondly, it greatly retards the gravitational settlina of aerosol particles.

The basis of aerosol particle formation is the coagulation process. A suspersaturated mixture of vapor in inert gas is unstable; the vapor molecules collide and coagulate to form increasingly larger particles as a result of their Brownian motion. The growth in particle size as a function of time can be derived from basic coagulation theory, ${ }^{(4)}$ with the result

$$
d=d_{0}\left(1+k n_{0} t\right)^{1 / 3}
$$

where $d_{0}$ is the initial particle diameter, $d$ is the particle diameter at a later time, $t ; n_{0}$ is the inital particle concentration (particles $/ \mathrm{cm}^{3}$ ), and $K$ is the coagulation "constant", approximately $2 \times 10^{-9} \mathrm{~cm}^{3} / \mathrm{sec}$. It is informative to consider two specific examples of particle growth by coagulation, a low vapor density case and a high vapor density case: The low vapor density case $\left(P_{L i} \stackrel{\bumpeq}{=} 10^{-2}\right.$ torr, $\left.n_{0}=3.2 \times 10^{14} / \mathrm{cm}^{3}\right)$ corresponds roughly to aerosol formation in inert gas just above a pool of liquid lithium at $1000^{\circ} \mathrm{F}$. Table I lists the theoretical growth in aerosol particle size with time. During the time required for vapor diffusion through the 
boundary layer above the pool, i.e., 0.1 to 1 second, a very fine aerosol

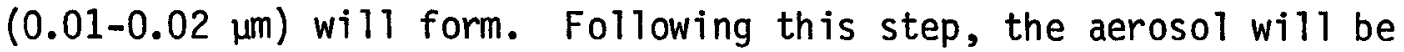
transported away from the vicinity of the boundary layer by convection and/or diffusion. In a closed system, such as the bell jar apparatus employed here, the subsequent history will involve a gradual buildup of the fine aerosol throughout the system and secondary coagulation into larger particles. The ultimate mass concentration and particle size will be determined by gravitational settling and wall deposition processes, which balance out the aerosol formation process. Aerosol mass concentrations can easily approach one order of magnitude higher than that of the initial vapor density, and particle sizes can approach $5 \mu \mathrm{m}$. In summary, in a closed system with a low pressure lithium vapor source, aerosol builds up by the initial formation of very fine particles near the vapor source and subsequent agglomeration as these particles are transported into the cover gas by convection.

The high vapor density case $\left(P_{L i}=1000\right.$ torr, $\left.n_{0}=3.2 \times 10^{19} / \mathrm{cm}^{3}\right)$ corresponds roughly to aerosol formation following a large, transient increase in lithium vapor pressure; such a transient has been predicted to occur after each laser fusion explosion. Both the aerosol growth behavior and the resulting optical influence are dramatically different from the preceding case. From Table II it is seen that within 1 microsecond, aerosol capable of scattering light* has been formed. After 10 microseconds, the aerosol is of sufficient size (and number) to produce a $20 \%$ per meter 1oss in light passing through it. Further growth in aerosol size increases the light loss per meter in proportion to the cube of the particle size until a maximum is reached at a diameter of about $0.2 \mathrm{\mu m}$. It should be noted that wall "pumping" of the lithium vapor would be too slow to prevent the formation of this aerosol in a large vesse1. One concludes that a large amount of optically dense aerosol could easily be formed under the above conditions. A critical requirement for its occurrence is the supersaturation of the lithium vapor at some time during the transient pressure cycle. The likelihood of supersaturation is not known at present and should be examined.

*A discussion of optical effects from aerosol is given in a later section of this report. 


\section{TABLE I}

\section{COAGULATION OF LOW DENSITY VAPOR IN INERT GAS,}

$P_{L i}=10^{-2}$ torr, $n_{0}=3.2 \times 10^{14} / \mathrm{cm}^{3}$

Elapsed Time ( $\mathrm{sec})$

Particle Diameter ( $\mu \mathrm{m})$

$\begin{array}{ll}10^{-1} & 0.011 \\ 1 & 0.024 \\ 10 & 0.052 \\ 100 & 0.11 \\ 1,000 & 0.24 \\ 10,000 & 0.52\end{array}$

TABLE II

COAGULATION OF HIGH DENSITY VAPOR ONLY

$P_{L i}=1000$ torr, $n_{0}=3.2 \times 10^{19} / \mathrm{cm}^{3}$

Elapsed Time (sec)

Particle Diameter ( $\mu \mathrm{m})$

$\begin{array}{ll}10^{-6} & 0.011 \\ 10^{-5} & 0.024 \\ 10^{-4} & 0.052 \\ 10^{-3} & 0.11 \\ 10^{-2} & 0.24 \\ 10^{-1} & 0.52\end{array}$




\subsection{Literature Search}

A computer assisted literature search of Chemical Abstracts, Engineering Index, Nuclear Science Abstracts, and NTIS data bases failed to reveal any previous studies related to the formation of lithium aerosol in the cover gas above pure liquid lithium. A considerable volume of work has appeared, however, concerning liquid sodium systems involved in LMFBR development. Most of these reports are concerned with sodium oxide, hydroxide or carbonate aerosols which are formed as a result of a sodium fire or leak in an air atmosphere. This work is not directly relevant to aerosol formation in the inert gas systems, which has only received very limited study.

In 1970 a research program was initiated at Argonne National Laboratory ${ }^{(5)}$ to study the extent, kinetics and mechanism of sodium aerosol formation relevant to LMFBR cover gas systems. It was felt that sodium aerosol could interfere with control-rod drive units and other mechanical parts of the reactor. In fact, aerosol was shown to be a contributing factor in the oxidation and sticking of the rotating-plug freeze seals in EBR-II. (5) over a two year period these seals collected $\$ 150 \mathrm{lb}$ of sodium from the cover gas.

Preliminary experiments at ANL involved visual observations of a sodium pool with an argon stream flowing across the surface at atmospheric pressure. At $200^{\circ} \mathrm{C}$ no aerosol was visible, but at $300^{\circ}$ and above, a haze could be seen and collected on a filter. Semi-quantitative results indicated that at $400^{\circ} \mathrm{C}$ the sodium aerosol concentration could exceed the concentration resulting from the vapor pressure by a factor of 10 .

An attempt was also made to determine the particle size of the sodium aerosol in these experiments. Figure 1 shows the results from inertial separation of the aerosol using a cascade impactor. The data obey a log-normal distribution with a mass mean diameter $\checkmark 4 \mu \mathrm{m}$, i.e., 50 weight percent of the aerosol was present as particles with diameters $<4 \mu \mathrm{m}$. Experiments performed by Murata et al ${ }^{(6)}$ in Japan produced particles in the size range 1.8-2.6 $\mu \mathrm{m}$ using essentially the same apparatus and conditions as the ANL workers. 
An interesting extension of the ANL work involved the substitution of helium for argon as the sweep gas. At the same temperatures and gas flow rates, appreciably less sodium aerosol was collected in a given time for helium compared to argon. Since the experiments involved a dynamic gas sweep, we can conclude that sodium aerosol is generated at a greater rate in argon. The main conclusions that can be drawn from these sodium studies are, firstly, that aerosol generation increases with increasing temperature and can reach sufficiently high concentrations to be clearly visible to the naked eye. Secondly, the particle size of the aerosol will generally be in the size range $<10 \mu \mathrm{m}$. Thirdiy, a difference might be expected in the kinetics, and possibly extent, of aerosol formation with argon and with helium as cover gas. Significantly, however, no work has been reported on simple convection induced (no sweep gas) aerosols, particularly at gas pressures below atmospheric. It is precisely these conditions which may prevail in a laser fusion reactor system.

\subsection{Laser Beam Extinction and Visible Scattering by Alkali Metal Aerosol Particles}

Aerosol particles are efficient interceptors of light by means of reflection, absorption, and diffraction.*(7) In laser fusion applications one is concerned primarily with the combined loss of beam intensity by all three mechanisms. A convenient measure of this loss is the extinction coefficient, $b$, defined as the fractional loss in beam intensity per unit pathlength. In symbols

$$
b=\frac{\Delta I / I}{\Delta X}
$$

where $I$ is the beam intensity, and $\Delta I$ is the intensity loss over a distance $\Delta X$. A convenient set of units for $b$ in the discussion here is percent loss/meter.

*Refraction does not occur because alkali metal particles are opaque. 


\subsubsection{Experimental Estimation of Beam Extinction}

Beam extinction values mày be measured or estimated most directly with the aid of a low power laser of suitable wavelength. Since no unique wavelength has been proposed for laser fusion systems, but rather a range of possibilities from approximately 0.2 to $10.6 \mu \mathrm{m}$, it was decided to employ a He-Ne laser at $0.6328 \mu \mathrm{m}$ wavelength and $2 \mathrm{~mW}$ power for the present work.

Two techniques, shown schematically in Figures 2 and 3 , were considered for this work. The first method measures beam losses directly, based on the definition of extinction. For the experiment shown, the extinction coefficient,

$$
b=\frac{1}{L} \ln \left(\frac{I}{I}\right) \cong \frac{1}{L}\left(\frac{I_{0}-I}{I_{0}}\right)
$$

where $I_{0}$ and $I$ are the entering and exiting beam intensities, corrected for window losses, and measured with a silicon cell photometer. The beam path length is L. Window loss corrections may be eliminated by defining $I_{0}$ and $I$ as the intensities measured at the photometer, before and after the introduction of aerosol into the chamber. The major defect in this technique is its lack of sensitivity. For small extinction values (b $\sim 1 \%$ /meter) the difference between the two intensities, $I_{0}$ and $I$, is small and tends toward large error. In consequence this technique is best suited to the measurement of rather large extinction coefficients, i.e., $b \geqq 2 \% /$ meter.

The second technique, employing the qualitative visual detection of light scattered from the beam, is much more sensitive. Quantitative tests with dilute smoke, performed under this contract, established that the extinction coefficient corresponding to the lower limit of beam visibility was about $0.01 \% /$ meter. In addition some indication of aerosol particle size may be deduced from the angular dependence of beam visibility, and is discussed in the following section. 
For the present survey, experiments where speed and sensitivity were required, the visual detection method was chosen. A graphical sumary of various extinction coefficients is presented in Figure 4.

\subsubsection{Particle Size Effects}

The range of particle sizes of primary importance for the present experiments 1 ies between 0.01 and $10 \mu \mathrm{m}$; particles smaller than this tend to grow into this range by coagulation, while particles larger than this are formed slowly and are more susceptible to removal by gravitational settling.

Extinction per unit mass of aerosol depends strongly on the size of the aerosol particles. $(7,8,9)$ The highest values occur for particle diameters near $d_{m}=\lambda / \pi$, which for a He-Ne laser gives $d_{m}=0.2 \mu \mathrm{m}$. Above this diameter the extinction decreases because larger particles have less cross-sectional area per unit mass; below this diameter it decreases because the scattering mechanism changes to one with sharply decreasing efficiency (Rayleigh scattering, $d<<\lambda$ ). This behavior is evident in Figure 5 , in which the results of an approximate calculation of extinction coefficient vs. particle size are presented. A lithium aerosol concentration of $0.036 \mu \mathrm{g} / \mathrm{cm}^{3}$ was chosen as typical for the present experiments; for other concentrations the extinction coefficient would scale proportionately. An important feature of this graph is the relatively sharp decrease in extinction coefficient for the smaller particle diameters. This suggests that in the earliest stages of aerosol formation where very fine particles predominate, the extinction coefficient might be quite low.

Some qualitative information on the aerosol particle size may be deduced from the angular dependence of the visible scattering. For particle sizes less than $1 / 10$ the wavelength employed, i.e., less than $0.06 \mu \mathrm{m}$ diameter, the scattering will be almost isotropic. In this case if 
sufficient numbers of these fine particles are present, the beam will be visible even at $90^{\circ}$ from the beam direction. In sharp contrast, for particle sizes larger than one wavelength, i.e., $0.63 \mu \mathrm{m}$, the beam scattering will become very much stronger in the forward direction so that it might easily be visible at $20^{\circ}$ but invisible at $90^{\circ}$.

\section{FACILITIES AND MATERIALS}

The major facilities utilized in the experimental portion of this program were the Experimental Lithium Facility (ELF) shown isometrically in Figure 6 and the Bell Jar Apparatus (BJA) shown in Figure 7. The ELF system, shown schematically in Figure 8 is an all austenitic stainless steel loop designed for $5 \mathrm{gpm}$ flow and a hot leg sample section temperature of $538^{\circ} \mathrm{C}\left(1000^{\circ} \mathrm{F}\right)$, and a $\Delta \mathrm{T}$ of $149^{\circ} \mathrm{C}\left(300^{\circ} \mathrm{F}\right)$. The main loop system is of all welded construction and uses $25 \mathrm{~mm}$ (1") 0.0 . X $1.65 \mathrm{~mm}\left(0.065^{\prime \prime}\right)$ wall Type 304 stainless stee 1 tubing. The total 1 ithium inventory is $13.6 \mathrm{~kg}(30 \mathrm{lb})$. Test samples are located in the hot leg and cold leg test sections and may be periodically removed into the controlled atmosphere glove box to give the time dependency of the mass transfer rates.

The lithium flows from the electromagnetic pump progressively through the flowmeter, the shell side of the cold leg economizer (heat exchanger), a heater section, an isothermal hot leg test section, the tube side of the economizer and a finned tube heat exchanger.

Also included in the system are four separate sub-10ops or bypass lines, which function as cold trap and hot trap facilities, an instrumentation section for impurity monitoring and a flow through sampler station. These sub-1oops constructed of $12.7 \mathrm{~mm}\left(0.500^{\prime \prime}\right) 0 . D . \times 1.65 \mathrm{~mm}$ (0.065") wall 304 stainless tubing are used to monitor and control the lithium impurity content. 
The glove box may be located over either the hot or cold legs of the system and enables the withdrawal of samples to be performed while loop operation continues. The argon atmosphere purity is maintained by means of a self contained dry train.

The ELF system is used as a lithium supply source to the BJA, the pot in the latter being filled with lithium by the establishment of a pressure differential between the BJA and the ELF dump tank. The BJA consists of an evacuable glass bell jar connected to a CVC vacuum system equipped with a roughing pump and a liquid nitrogen trapped diffusion pump. The bell jar, which is approximately $0.76 \mathrm{~mm}$ (30 inches) high $\times 0.46 \mathrm{~m}$ (18 inches) in diameter rests on a rubber seal which mates to a flat stainless steel flange unit. Suspended from the inside of the BJA flange is a small pot approximately $200 \mathrm{~m}$ ( 8 inches) long $\times 76 \mathrm{~mm}$ ( 3 inches) in diameter, in which the lithium is contained. The pot is wrapped with a flexible trace heater connected to a controller. The lithium temperature is monitored with a sheathed thermocouple in a thermowell placed such, that it indicates the near surface temperature of the lithium pool. The flange is also equipped with viewing ports for transmission of the laser beam through the atmosphere above the 1ithium pool and for observation at $90^{\circ}$ to the beam direction. Pressure measurement was achieved by means of a thermocouple gage attached directly to the flange, by a Wallace-Tiernan gage reading from one atmosphere to one torr, and by the vacuum gages incorporated in the main CVC vacuum unit. The atmosphere in the bell jar was controlled by a series of gas valves leading to high purity argon or helium gas cylinders.

The laser utilized in these experiments, a Metrologic Instruments, Model ML-650, 2.0 milliwatts helium-neon laser, emitted visible red light and was located in the experimental set up as shown in Figure 7 .

The lithium used in this program was originally supplied by Foote Mineral Company in the form of two-pound ingots of nominal purity $99.98 \%$, and was introduced to the BJA pot via the ELF system dump tank. Major metallic 
impurities in the lithium are sodium and potassium, with nitrogen, oxygen and hydrogen being the major non-metallic impurities. Table III summarizes the available analytical information on the lithium chemistry of the ELF system; the data were obtained utilizing flow-through samplers. This table also incorporates the analytical results on a duplicate sample, which were obtained by courtesy of V. Maroni of Argonne Nationa1 Laboratory.

TABLE III

SUMMARY OF LITHIUM ANALYSES FROM EXPERIMENTAL LITHIUM FACILITY

\begin{tabular}{|c|c|c|c|}
\hline$\underset{\#}{\text { Samp }}$ le & $\begin{array}{l}\text { Analysis } \\
\text { Nitrogen }\end{array}$ & $\begin{array}{r}\text { (ppm) } \\
\text { Oxygen }\end{array}$ & Remarks \\
\hline 1 & 181 & $N A^{*}$ & $\begin{array}{l}\text { After filling loop - entire loop isothermal } \\
\text { a } 600 \text { of }(3160 \mathrm{C})\end{array}$ \\
\hline 2 & 205 & 608 & $\begin{array}{l}\text { Loop isothermal a } 6000 \mathrm{~F}(3160 \mathrm{C})-\text { cold } \\
\text { trap operated for } 120 \mathrm{~h} \text { ( } 4000 \mathrm{~F}(2040 \mathrm{C})\end{array}$ \\
\hline 3 & $77 \star \star$ & NA & $\begin{array}{l}\text { Loop isothermal o } 6000 \mathrm{~F}(3160 \mathrm{C})-\text { hot } \\
\text { trap operated for } 70 \mathrm{~h} \text { (0 } 1000 \mathrm{OF}(5380 \mathrm{C})\end{array}$ \\
\hline 4 & 104 & NA & $\begin{array}{l}\text { Loop operated for } 378 \mathrm{~h} \text { a } 1000 \mathrm{~F} \\
\text { (5380C), dumped, ref } 111 \text { ed, cold trapped } \\
72 \mathrm{~h} \text { o } 400 \text { of }(2040 \mathrm{C})\end{array}$ \\
\hline 5 & 107 & 112 & $\begin{array}{l}\text { Loop operated for } 450 \mathrm{~h} \text { a } 1000 \mathrm{oF} \\
(5380 \mathrm{C}) \text { hot trapped } 71 \mathrm{~h} \text { a } 1000 \mathrm{oF} \\
(5380 \mathrm{C})\end{array}$ \\
\hline
\end{tabular}

*NA - not available

**Same average number reported in duplicate analys is performed by $V$. Maroni (ANL).

\section{EXPERIMENTAL TECHNIQUES}

After filling the lithium pot to the desired level, the lithium was allowed to equilibrate with the stainless steel pot by means of an overnight hold at $260^{\circ} \mathrm{C}\left(500^{\circ} \mathrm{F}\right)$. A small quantity of titanium chips was located in the bottom of the pot to perform a gettering function at high temperatures. 
While the lithium and pot were reaching equilibrium, the portable laser and viewing shroud were installed, so that the laser beam was directed over the surface of the lithium pool at a vertical distance of $s 76 \mathrm{~mm}$ ( 3 inches). The lithium contained approximately 0.02 weight percent impurities, mainly sodium and potassium and was representative of commercially available, low sodium grade metal. No additional purification, other than reaction with the titanium chips located in the bottom of the pot was performed at this stage. Studies planned for subsequent programs will utilize lithium from which the sodium and potassium impurities have been removed by distillation. The lithium temperature was raised to the desired temperature e.g., $427^{\circ} \mathrm{C}\left(800^{\circ} \mathrm{F}\right)$ and after an overnight hold, the aerosol experiments were initiated. At this time, the lithium surface exhibited a mirror-like appearance, with no impurity scum visible. The laser beam was observed in two directions: approximately $20^{\circ}$ from the beam direction, where forward scattering produced a visible beam and at right angles to the beam direction for sideways scattering. The pressure range $10^{-1}$ torr to 300 torr was monitored for both argon and helium. The presence of aerosol particles above the lithium pool was clearly indicated by the visibility of a pencil-like beam of red laser light, with the beam intensity dependent on the pressure. Disappearance of the beam and hence absence of aerosol particles, at the limit of detectability with the naked eye was determined for each temperature. In Figure 9, the visible laser beam can clearly be seen as a thin, pencil like red beam running across the lithium pool.

Before making an observation at a particular pressure leve1, the BJA was alternately pressurized with argon (or helium) and then evacuated to the desired pressure. By this means, it was possible to ensure that aerosol particles from the previous pressure level determination did not interfere with the current determination. The determination of aerosol presence or absence was then only made after an equilibration period, which varied from one hour to an overnight hold. In this way, a series of determinations of aerosol formation (beam visibility) were made over a range of pressures at one temperature, followed by a similar series at different temperatures, using both argon and helium as the covergas. 


\section{RESULTS AND DISCUSSION}

The data obtained using this technique for lithium aerosol formation are plotted in Figures 10 and 11 for an argon and helium covergas, respectively. The presence or absence of aerosol is shown as a relationship between covergas pressure (torr) versus lithium vapor pressure (torr) over the temperature range $306-538^{\circ} \mathrm{C}\left(583-1000^{\circ} \mathrm{F}\right)$. The demarcation line between aerosol visibility and invisibility has been drawn as the best straight line through the data and provides a semi-quantitative measure of lithium aerosol formation and stability, with in the previously stated 1 imits of the experiment. A noticeable difference between the slope and location of this line for argon as compared to helium can clearly be seen.

Laser beam visibility increased slowly with time in agreement with the postulated accumulation and coagulation model discussed earlier. The absence of aerosol for very low lithium vapor pressures $\left(\backsim 3 \times 10^{-4}\right.$ torr) is understandable in terms of the coagulation and optical scattering theory presented.

The dependence on cover gas pressure $\left(10^{-2}\right.$ to 300 torr $)$ and species (argon, helium) is not clearly understood. All of the aerosol formation and deposition processes (evaporation, diffusion, coagulation, convection, wall deposition, gravitational settling) are affected to some degree by changes in the cover gas. It is thought that perhaps convection and gravitational settling may be the most strongly influenced processes but more detailed experimental work would be required to confirm this.

This new lithium data, taken in conjunction with the sparse reports for sodium might enable at least a preliminary theory of aerosol formation to be formulated. In particular, the different behavior with argon and helium cover gases is qualitatively reproduced in the two liquid metal systems. This difference might well be relevant, when the choice of cover gas for fusion reactors is made. 
5. CONCLUSIONS

The temperature/cover gas regime in which detectable thermat lithium aerosol is formed has been mapped for argon and helium cover gases. These results indicate that conditions of $1000{ }^{\circ} \mathrm{F}$ and a pressure of $10^{-1}-10^{-2}$ torr represent a border 7 ine case in which thermal aerosol may be detectable in argon. The aerosol particle density, however, at these temperatures and pressures, would be so low that the percentage loss in laser beam intensity is likely to be $<1 \%$ /meter. With helium as the support gas this intensity loss would be even smaller. In addition, the experimental conditions in this study were more conducive to aerosol formation than in a fusion reactor. For example, the bell jar system provided high thermal gradients which would be absent in a reactor cavity. Also, long equilibration times were allowed for the formation of aerosol.

In the real reactor system, very high intensity mechanical and thermal disturbances will be made to the liquid lithium. These disturbances, particularly transient increases in lithium vapor pressure appear to be capable of producing high concentrations of optically-dense aerosol, and should be the subject of any future work in this area.

\section{RECOMMENDATIONS}

In the light of the above statements, we suggest that a more detailed study of lithium aerosol formation is appropriate using the basic information contained in this report as a starting point. These future studies should include:

\section{A. Basic Studies}

- Kinetics of aerosol formation and occurrence of supersaturated vapor during very fast vapor pressure transients.

- Effect of sodium and potassium impurities on lithium aerosol. 
B. Reactor Oriented Studies

- Effect of transient lithium vapor pressure increases on aerosol formation.

o The use of 'cool' lithium sprays to condense 'hot' lithium vapor/aerosol.

- Effect of lithium agitation (falls, jets, splashing, etc.) on aerosol formation.

\section{REFERENCES}

1. W. R. Meier and J. A. Maniscalco, "Liquid Metal Requirements for Inertial Confinement Fusion, in "Materials Considerations in Liquid Metals Systems for Power Generation," pp. 23-31, National Association of Corrosion Engineers, Houston, TX, 1978.

2. J. Hovingh, J. A. Maniscalco, M. Peterson and R. W. Werner, "The Preliminary Design of a Suppressed Ablation Laser-Induced Fusion Reactor", in "Proceedings of the 1st Topical Meeting on the Technology of Controlled Nuclear Fusion," CONF-740402-P1, April 1974, pp. 96-111.

3. J. A. Manisca1co, J. A. Blink, J. Hovingh, et al, "A Laser Fusion Power Plant Based on a Fluid Wall Reactor Concept", presented at the "Proceedings of 3rd Topical Meeting on the Technology of Controlled Nuclear Fusion, American Nuclear Society, Sante Fe, NM, 1978.

4. G. M. Hidy and J. R. Brock, The Dynamics of Aerocolloidal Systems, Pergamon Press, New York, 1971.

5. G. M. Kesser, "Sodium Technology Quarterly Report,Apri1, May, June 1970," ANL/ST-3, September 1970. 
G. M. Kesser, "Sodium Technology Quarterly Report, July-September 1970," ANL/ST-4, December 1970.

6. M. Murata, M. Naritomi, Y. Yoshida and M. Kokubu, J. Nucl. Sci. Tech., 11, pp. 65-71, (1974).

7. S. K. Friedlander, Smoke, Dust, and Haze: Fundamentals of Aerosol Behavior, pp. 175-208, John Wiley, New York, 1977

8. A. P. Waggoner and R. J. Charlson, "Measurements of Aerosol Optical Parameters", in "Fine Particles: Aerosol Generation Measurements Sampling and Analysis", pp. 512-533, Academic Press, New York, 1976.

9. F. R. Faxvog, "Optical Scattering per Unit Mass of Single Particles", Appl. Opt., 14, №. 2, pp.269-270, (1975). 


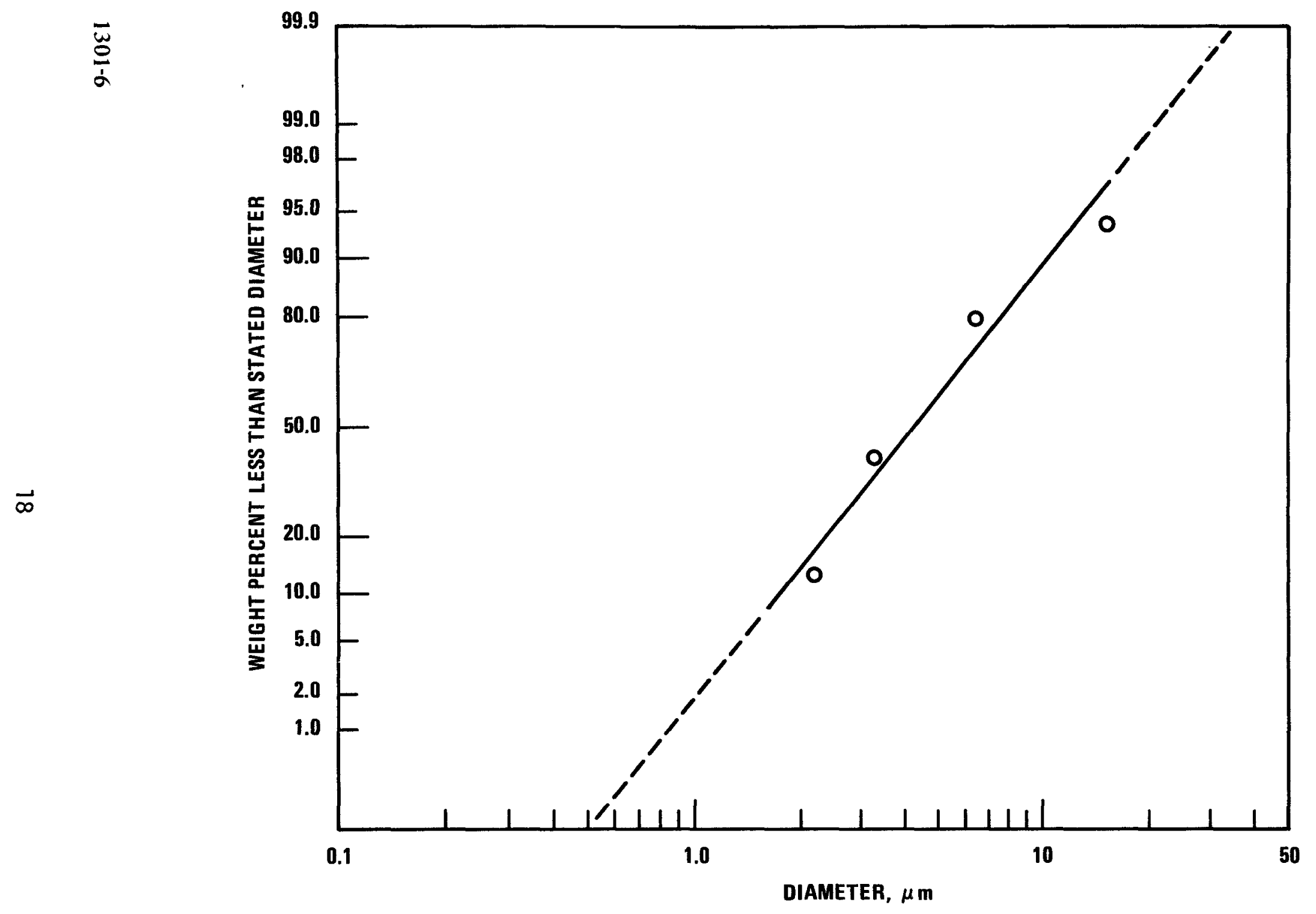

Figure 1. Particle-Size Distribution of Sodium Aerosol above Sodium at $400^{\circ} \mathrm{C}$. (5) 


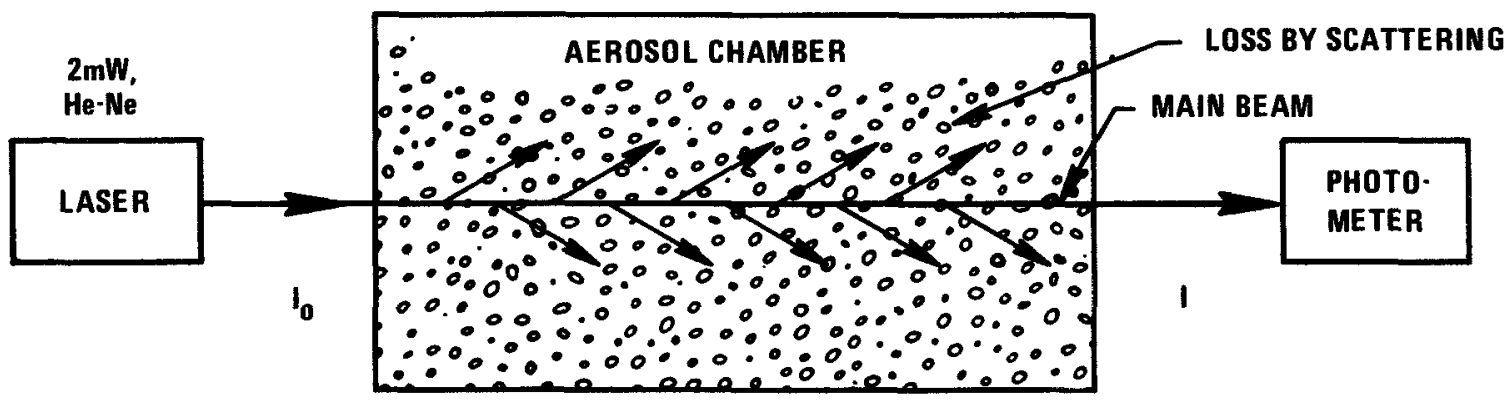

Figure 2. Direct Measurement of Beam Losses, Useful for Extinction Coefficients $>2 \% /$ Meter.

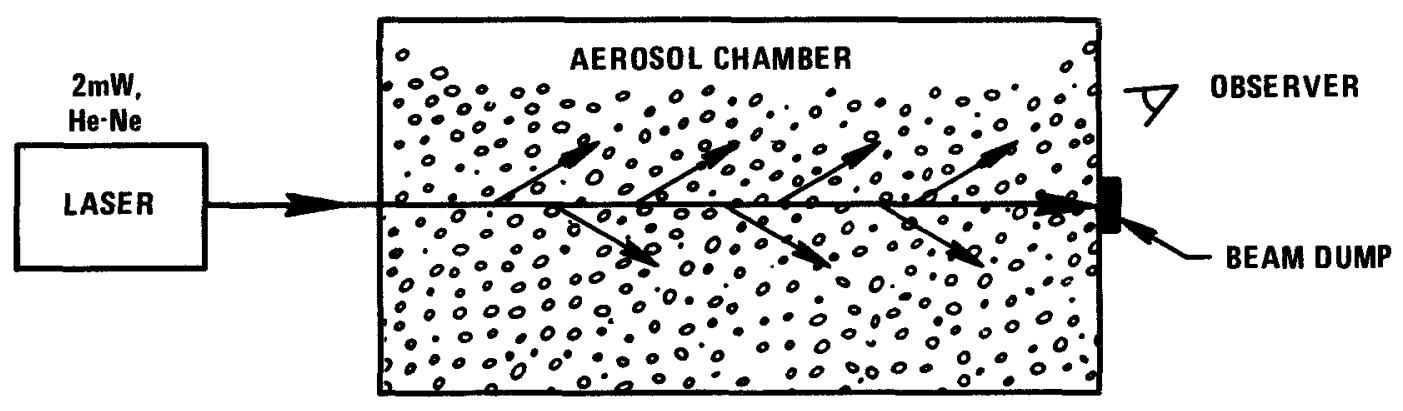

Figure 3. Visual Detection of Beam Losses, Useful for Extinction Coefficients $>0.01 \% /$ Meter.

1301-5 


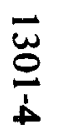

EXTINCTION COEFFICIENT, b (\%/LOSS/METER)

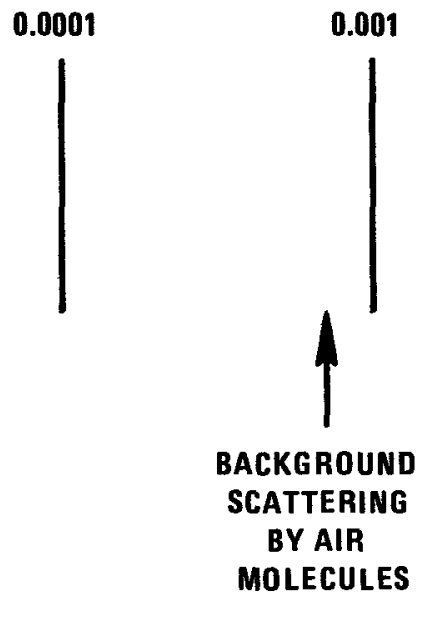

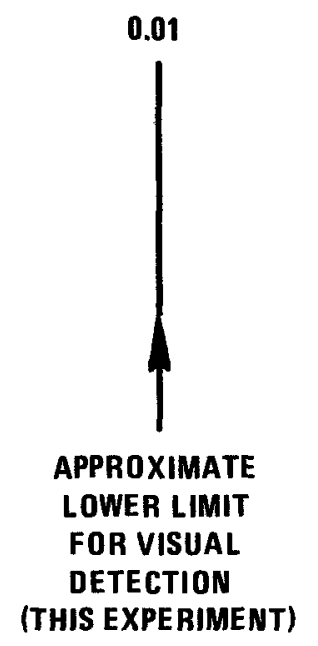

F
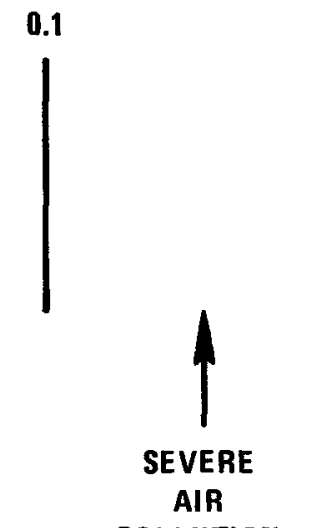

POLLUTION

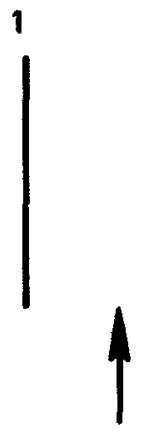

APPROXIMATE

LOWER LIMIT

FOR PHOTOMETER (THIS EXPERIMENT)
10

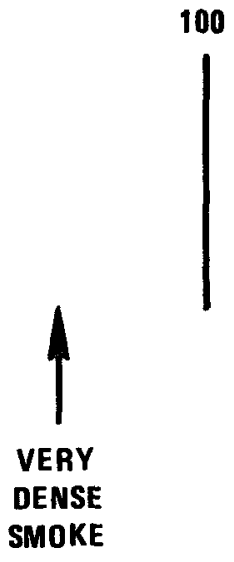

VISIBLE SCATTERING

SIGNIFICANT LOSS

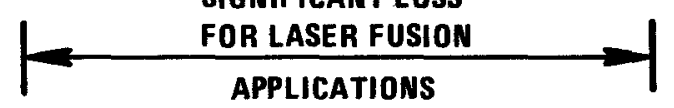

Figure 4. Extinction Coefficients for Various Laser Situations. In the Present Experiments a $2 \mathrm{~mW}$ He-Ne Laser (0.6328 $\mu \mathrm{m})$ was Employed. 


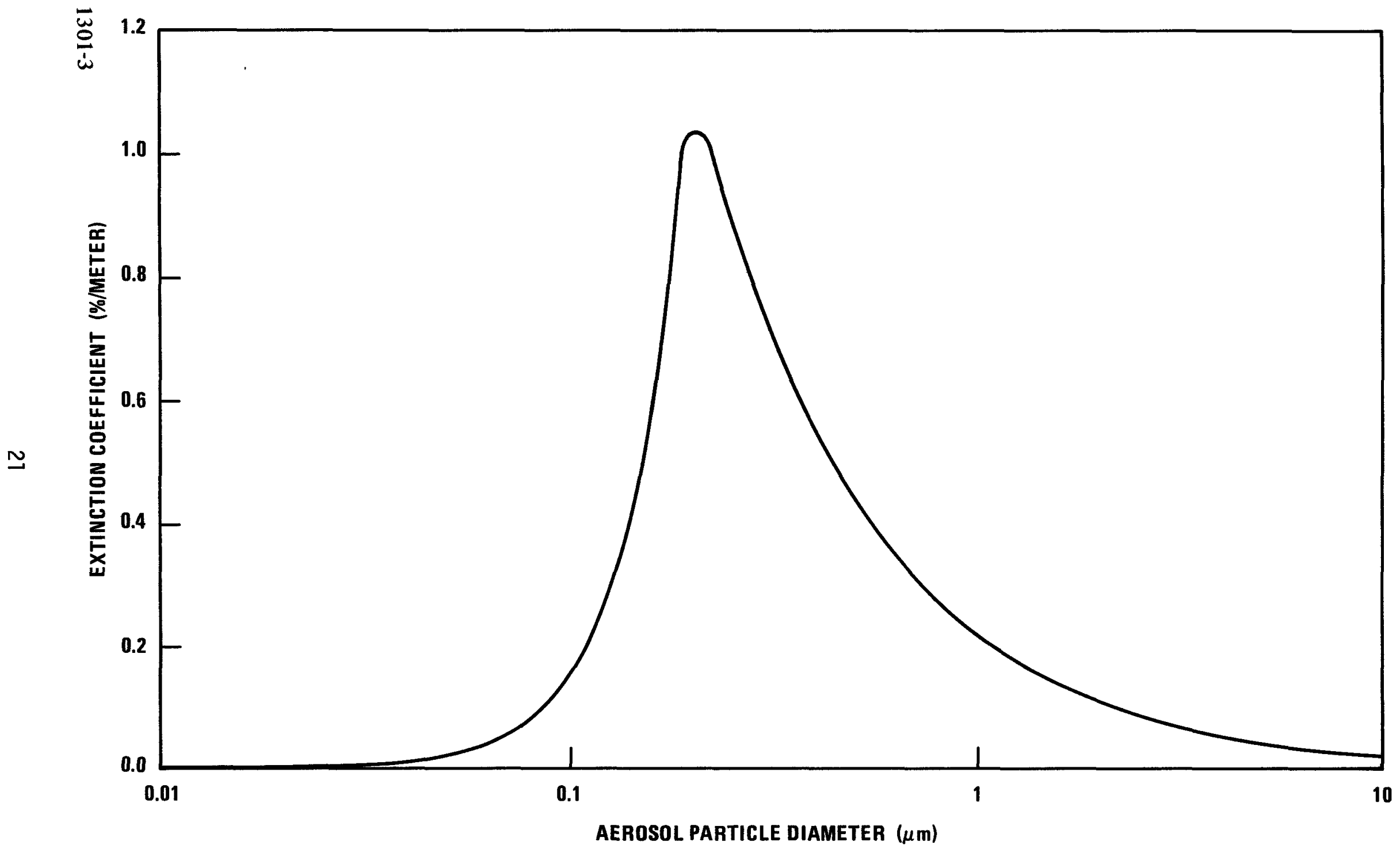

Figure 5. Theoretical Behavior of Extinction vs. Aerosol Particle Size, for a Fixed Mass Concentration of the Aerosol. Assumed Lithium Aerosol Concentration, $0.036 \mu \mathrm{g} / \mathrm{cm}^{3}$. 


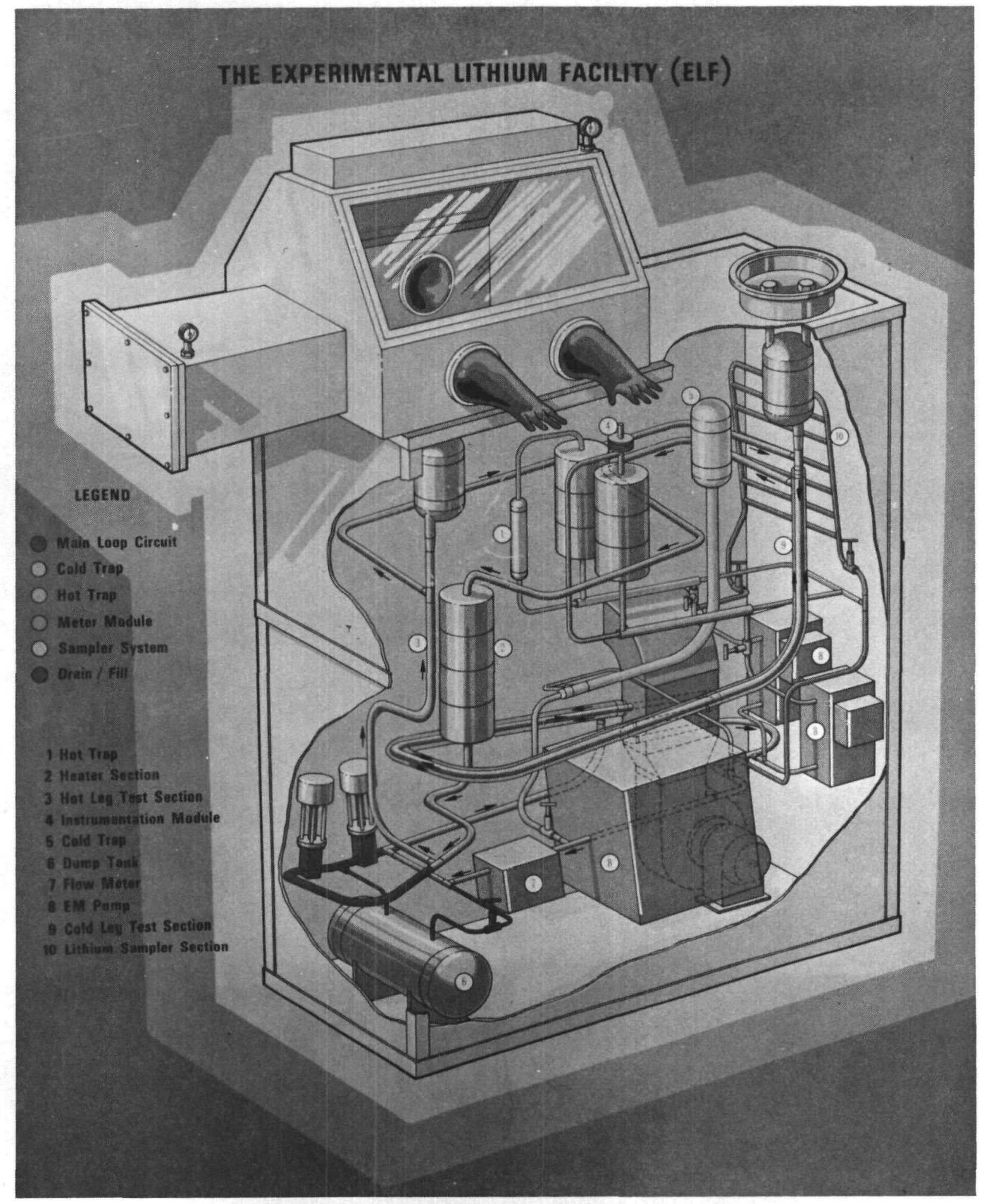

Figure 6. Isometric Picture of the Experimental Lithium Facility (ELF)

1301-1 


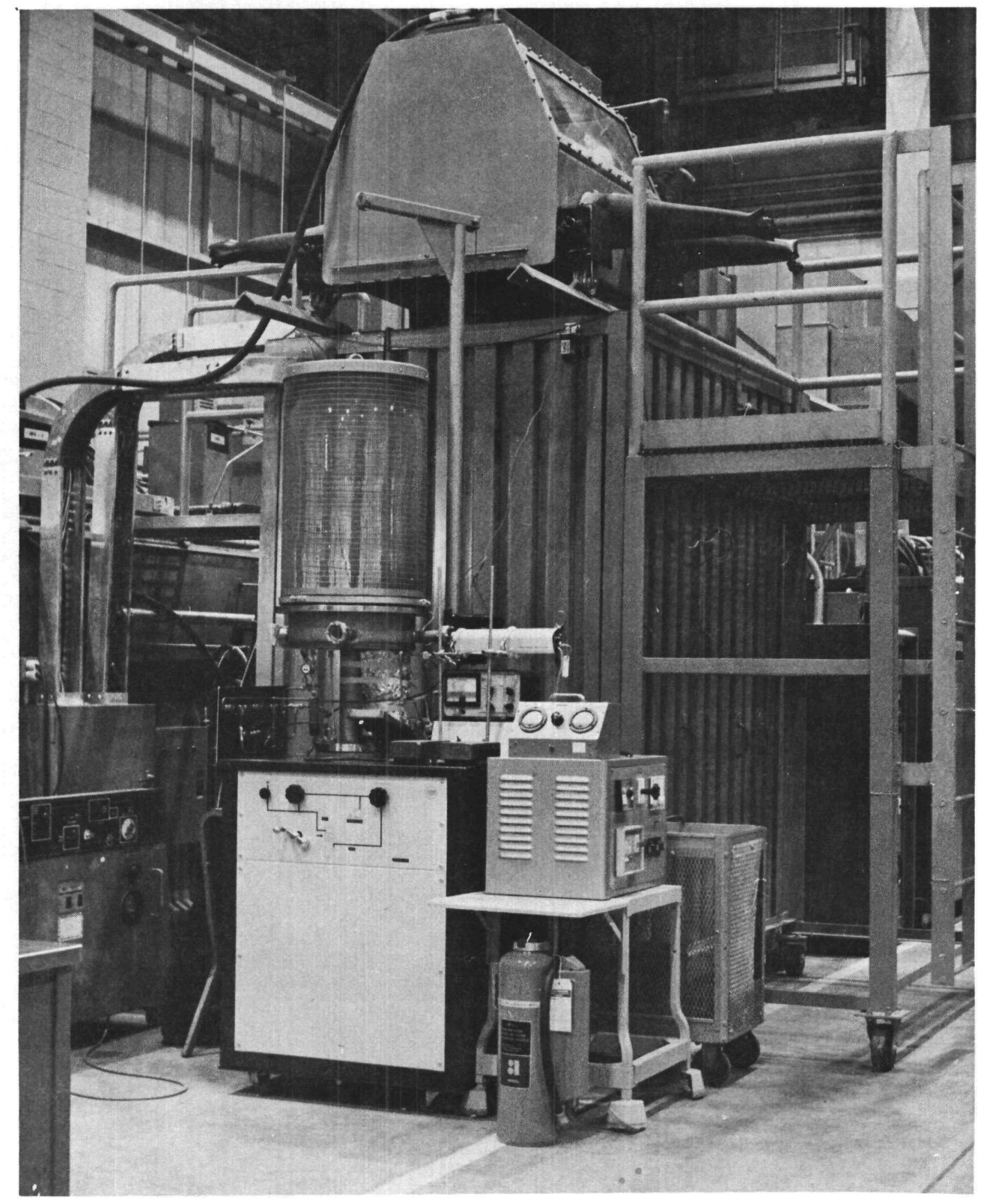

Figure 7. Photograph of the Bell Jar Apparatus (BJA) Used in the Lithium Vapor/Aerosol Studies 1301-2 


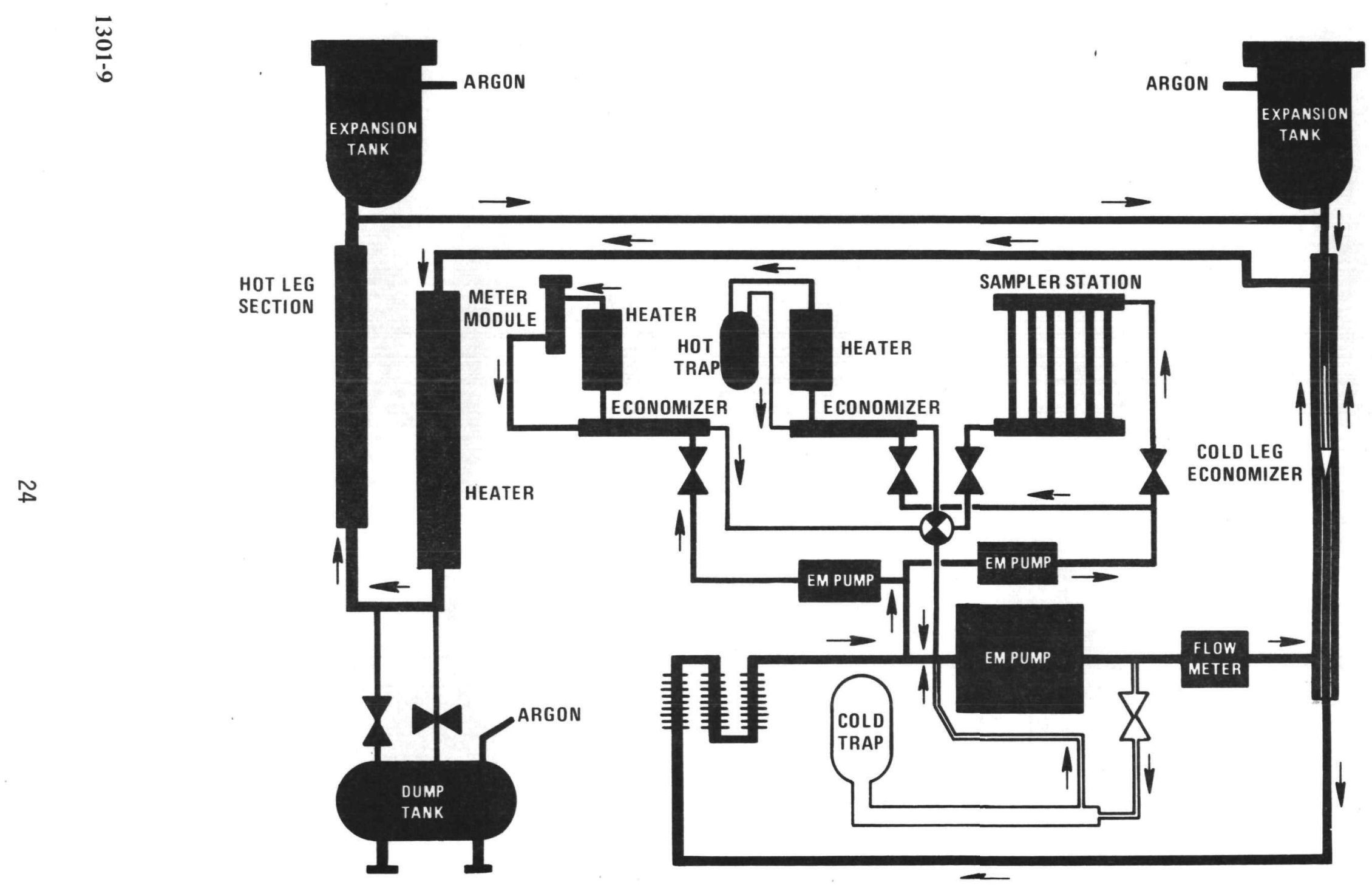

Figure 8. Schematic Representation of the Experimental Lithium Facility 


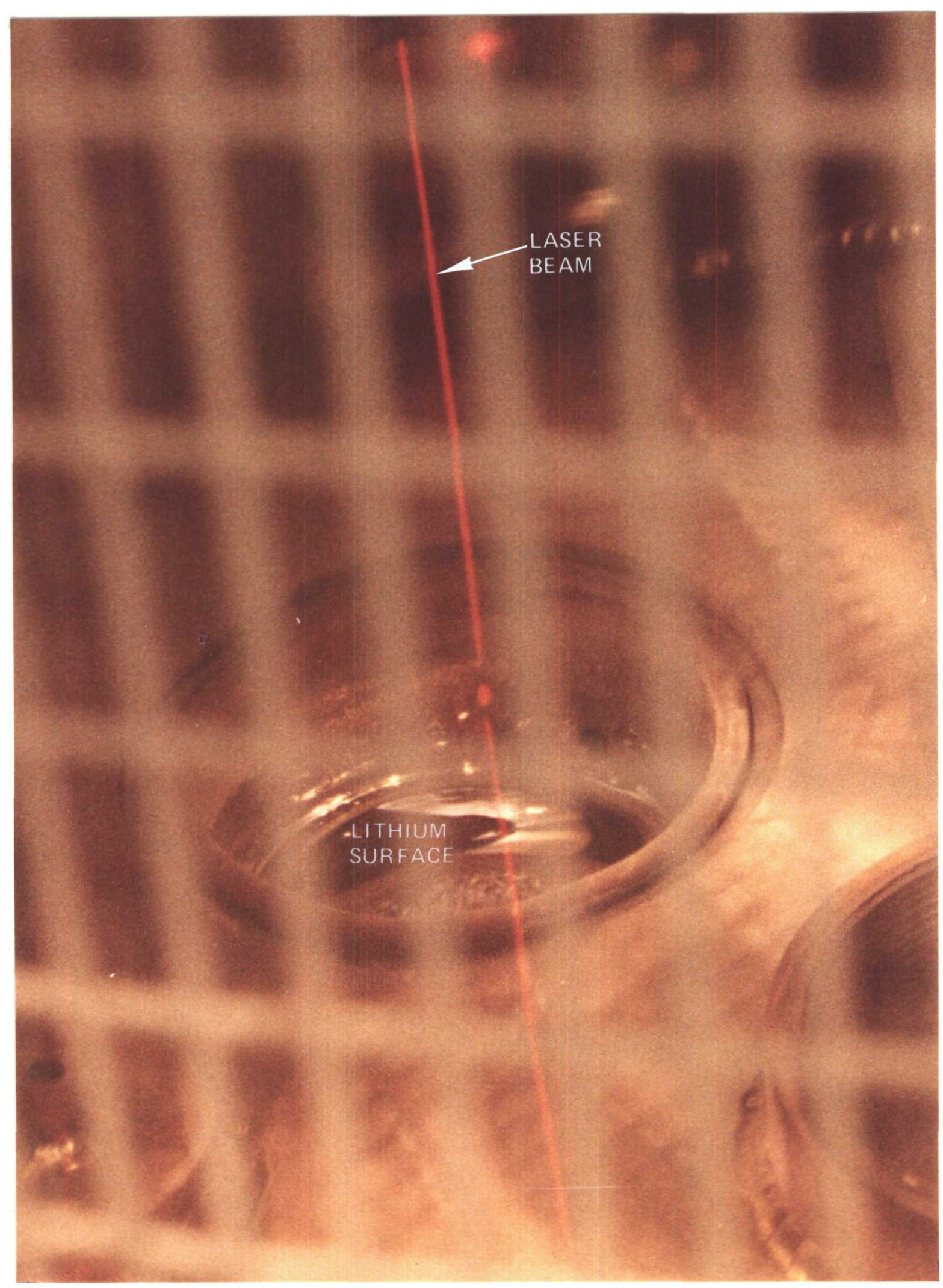

Figure 9. Photograph Showing a He-Ne Laser Beam Made Visible by the Presence of Lithium Aerosol Particles in the Bell Jar Apparatus 


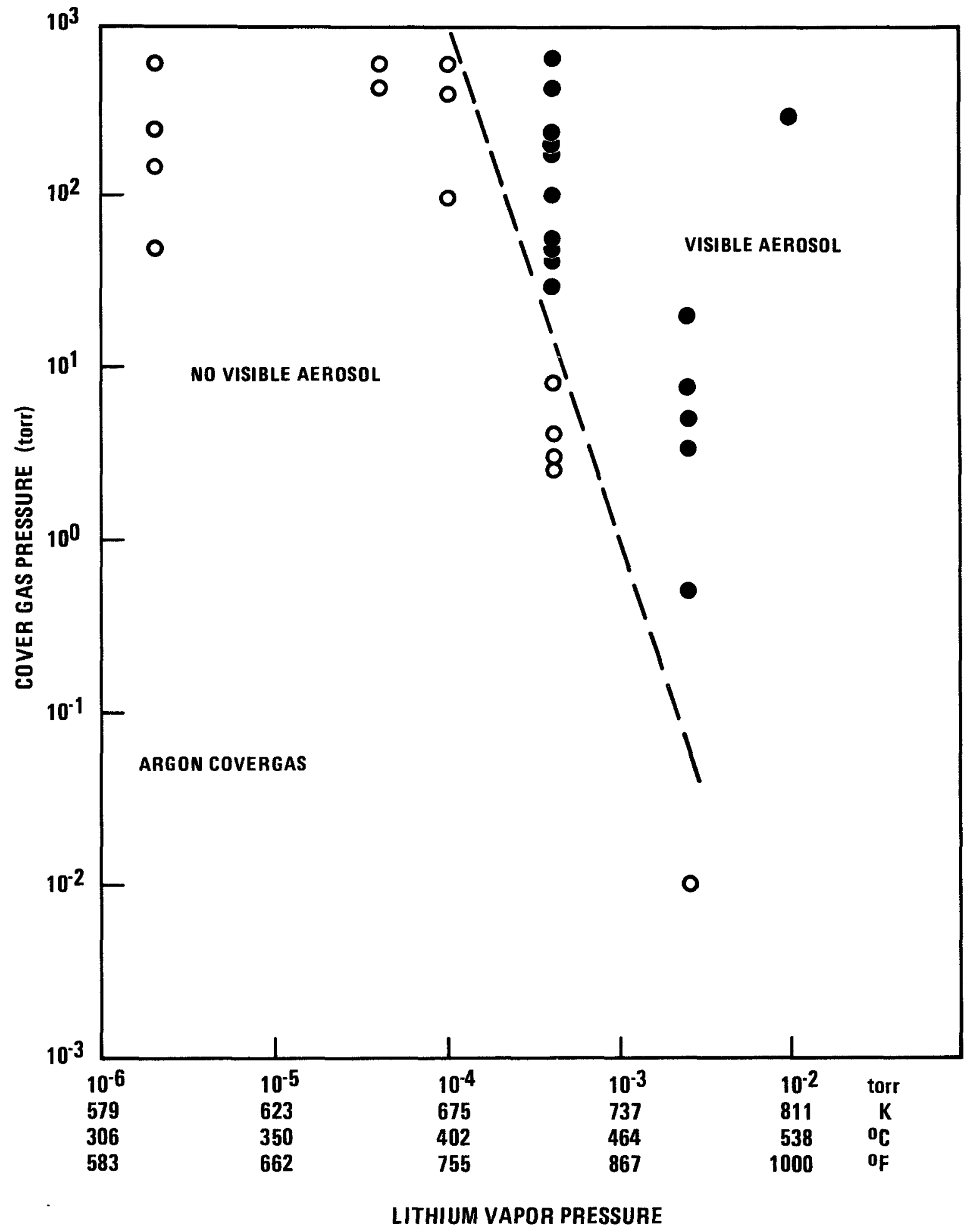

Figure 10. The Experimental Relationship Between Covergas Pressure and Lithium Vapor Pressure for the Formation of Lithium Aerosol Particles in Argon.

1301-8 


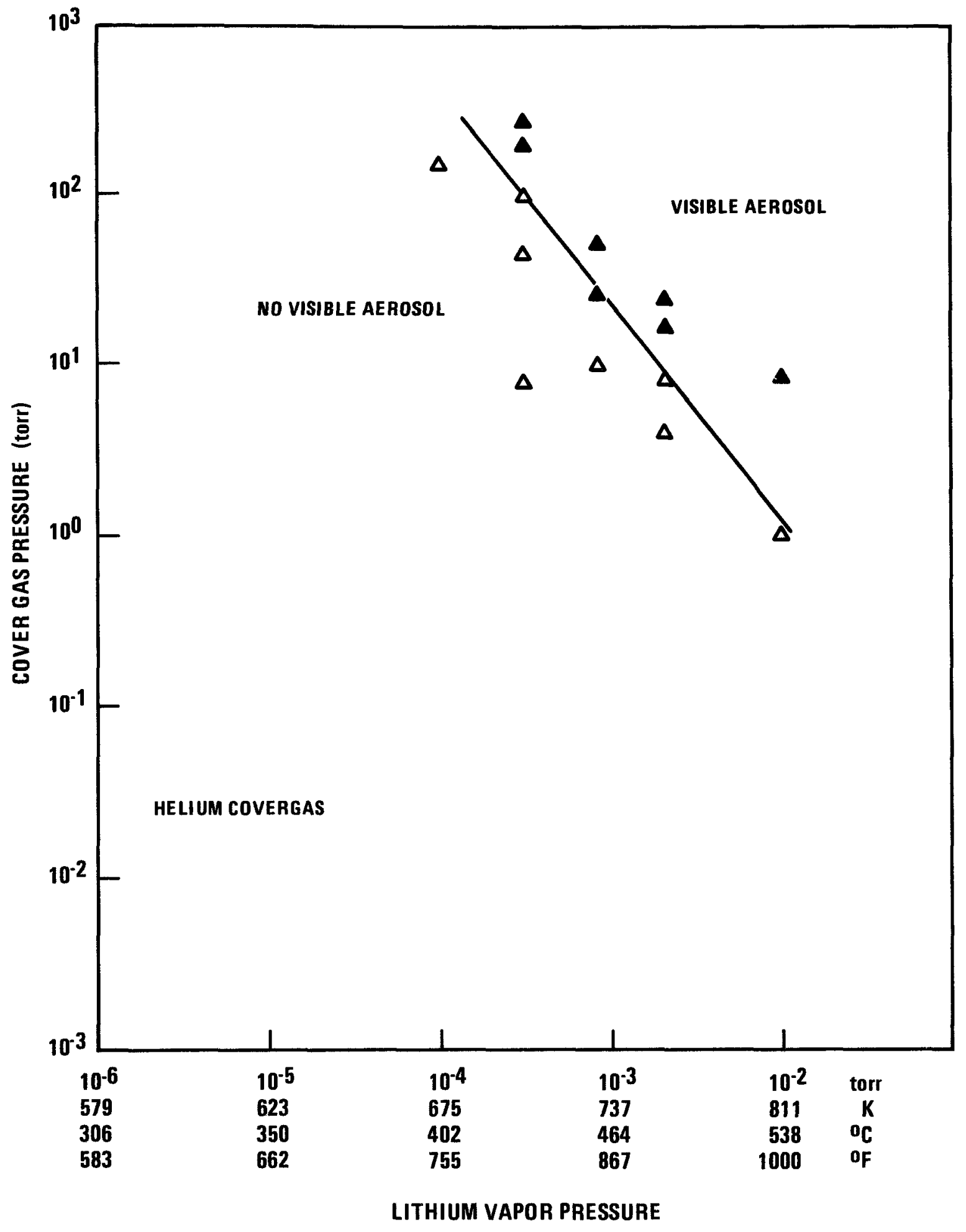

Figure 11. The Experimental Relationship Between Covergas Pressure and Lithium Vapor Pressure for the Formation of Lithium Aerosol Particles in Helium.

$1301-7$ 
Dr. Lawrence A. Booth

Los Alamos Scientific Laboratory

Mail Stop 5-29

Post Office Box 1663

Los Alamos, NM 87545

Lt. Co1. E. D. Braunschweig

Office of Laser Fusion, C-404

U.S. Department of Energy

Washington, DC 20545

Dr. Michael Monsler

Lawrence Livermore Laboratory

Post Office Box 5508

Livermore, CA 94550

Dr. C. E. Rossi

Office of Laser Fusion, C-404

U.S. Department of Energy

Washington, DC 20545

Dr. Roger B. Perkins

Los Alamos Scientific Laboratory

Post Office Box 1663

Los Alamos, NM 87545

Dr. John L. Emmett

Lawrence Livermore Laboratory

Post Office Box 5508

Livermore, CA 94550

Dr. G. Yonas

Sandia Laboratories

Albuquerque, NM 87145

Mr. R. B. Purcell (3 copies)

Contract Management Division

U.S. Department of Energy

Nevada Operations Office

Post Office Box 14100

Las Vegas, NV 89114

Technical Information Center

Oak Ridge, Tennessee

For distribution under TID-4500

Category UC-21 (214 copies) 


\section{INTERNAL DISTRIBUTION}

W-ARD
J. A. Corbett
B. R. Grundy
L. Kardos
W. E. Ray (2)
G. R. Taylor
G. A. Whitlow (6)
W. L. Wilson
J. E. Zerbe

W-R\&D CENTER

F. G. Arcella (2)

J. E. Bauer le

M. G. Down

J. K. Lowy

J. K. Hulme

W-FPSD
J. Chi
C. Flanagan
J. Karbowski
D. Kle in
T. Prevenslik
Z. Shapiro 